authors' version of Chapter 5, forthcoming in: Aarti Gupta and Michael Mason, eds. (2014) Transparency in Global Environmental Governance: Critical Perspectives. Cambridge, MA: MIT Press, pp. 107-131. (some editing corrections may appear in the final print)

\title{
Global Pesticide Governance by Disclosure: Prior Informed Consent and the Rotterdam Convention
}

\author{
Kees Jansen and Milou Dubois
}

Accounts of human suffering and environmental contamination in developing countries because of pesticide use often propose closing the knowledge gap between industrialized (pesticide-exporting) countries and developing (pesticide-importing) countries as a solution (Hough 1998). In such narratives, improved provision of information on pesticide risks and pesticide trade will enable developing countries to design and implement appropriate measures to control pesticide risks. This is the basic premise underlying the major global governance framework that addresses global pesticide flows, the Rotterdam Convention on the Prior Informed Consent Procedure for Certain Hazardous Chemicals and Pesticides in International Trade (hereinafter "the convention"). Transparency, in the form of governance by disclosure through prior informed consent (PIC), is the key pillar of the emerging global system of pesticide regulation. The PIC procedure stipulates that industry in exporting countries is allowed only to export listed chemicals after receiving consent of the importing country. The Rotterdam Convention calls for the sharing of information between states about hazardous chemicals entering international trade and about the regulatory actions taken in participating countries (Rotterdam Convention 2008). A basic concern of the convention is the differential capacity of countries to assess and manage potential risks posed by hazardous chemicals and pesticides (pesticides, the focus of this chapter, form the largest group of chemicals dealt with in the convention). In particular, the convention intends to support developing countries to make sound regulatory decisions.

Transparency, the opposite of secrecy, means deliberately revealing one's actions instead of hiding them (Florini 1998) and has, in this sense, a positive connotation. Recent research, however, has questioned the transparency turn in environmental governance and commented on the overvaluation of what transparency can achieve (Etzioni 2010). Scholars of transparency policies no longer assume a priori that the mechanism of transparency necessarily leads to accountable, legitimate, inclusive, and effective governance (Fung et al. 2007; Gupta 2008, 2010b). The debate has focused on two assumptions that underlie transparency initiatives (Gupta 2008). First, instead of mandating outcomes, priority is given to the establishment of procedures, which are seen as progressive, potentially emancipatory, 
and opening up the possibility for decision making by the participants themselves. The second assumption is that governance by disclosure can empower through the provision of information. Gupta questions these assumptions, arguing that because of different values behind its provision and interpretation, information itself is subject to conflict. In this critical theoretical reading, information about, for example, pesticide risks cannot be seen as a neutral force that will solve normative or political conflicts. Nor will access to information necessarily change power relations and improve the position of developing countries. Instead, contextual power relationships shape the effects of transparency. For example, transparency may increase inequality when poor nations cannot fulfill their transparency requirements or when recipients (in our case governments) are not able to understand disclosed information (Mol 2010). The perils of an undue emphasis on procedures in governance by disclosure include that "getting the process right" may divert resources from substantive outcomes, that procedures are left vague and open, and that those with power may undermine desired objectives by providing so much information that the receiving parties are not able to process it (“drowning in disclosure," Gupta 2008).

This chapter addresses some of the key questions raised by critical transparency studies for the Rotterdam Convention: we explore the extent to which the convention informs, empowers, or improves environmental performance or helps mitigate risk (Gupta 2010b). We will contextualize the convention by discussing Gupta and Mason's argument (this book, chapter 1) that the uptake of transparency is driven by democratization (responding to calls for open and more inclusive forms of collective choice) and marketization (the use of market-based and voluntary transparency in order to minimize market-restricting effects). Here, we will argue that without these drivers, the convention would not exist in its current form, but that other aspects, in particular the nature (or materiality) of the pesticide issue and classical notions of sovereignty, have also had a key impact and cannot be sidelined theoretically as secondary factors.

In developing our argument, we adapt Tyfield's characterization of different approaches to science policy, which also play a role in the formulation of risk management strategies (Tyfield 2012). First, a techno-statist Keynesian governance approach emphasizes that science delivers the facts about pesticide risks and provides the public good of risk information, which governments then use to regulate the complexities and uncertainties of a technological society (in this approach state, market, and society are distinctive spheres). Second, in a neoliberal approach, market actors best deliver risk information, and governance of risk preferably follows market principles (power is passed from professional technocratic elites to consumers who, it is argued, should have a free, though informed, choice about what pesticide they want to use). Third, a deliberative democracy approach to managing technological risk, making explicit tacit normative framings, prescribes risk management based on public participation and a democratized techno-science. Our hypothesis is that the first approach - the techno-statist Keynesian governance of risk-is the key driver for our case study of governance by disclosure. This challenges the theoretical prioritization of 
marketization and democratization as drivers. If our hypothesis turns out to be plausible, it will have consequences for the argument that the institutionalization of transparency decenters state-led regulation (Gupta and Mason, this book, chapter 1; see also Mol, this book, chapter 2).

The discussion about "transparency" in relation to governance tends to focus on information disclosure from governments to citizens (e.g., Fox 2007; Fung 2013). To stay true to the state-to-state disclosure focus of the Rotterdam Convention, and in line with the focus of this book, we prefer thus to use the term governance by disclosure. To date, the Rotterdam Convention is a relatively less-researched intergovernmental agreement. Most of the literature on the convention deals with its genesis or its legal basis (e.g., Langlet 2009; Selin 2010) but a discussion of its current role and wider implications as an example of governance by disclosure has yet to begin. Our analysis is based on available convention documents and databases, scholarly literature, and communications (interviews and e-mail exchanges) with five key actors (a former representative of an advocacy group, a designated national authority, a member of the chemical review committee, a pesticide company, and the convention secretariat) in 2011.

We proceed as follows: the next section describes the emergence of PIC in governing trade in hazardous chemicals, particularly the evolution from a right to know to informed consent. We then discuss institutionalization of the Rotterdam Convention's disclosure obligations and the implementation challenges as perceived by involved actors. Subsequently, we analyze the effects of this governance-by-disclosure regime by assessing whether it informs, empowers, or improves. The conclusion highlights the techno-statist nature of the convention and its disclosure-based governance approach.

\section{Embracing Transparency}

Since Rachel Carson's Silent Spring drew attention to the hazards of increased pesticide use, a vast literature has analyzed the divergent impacts of such use in developed and developing countries, with many more victims in the latter (e.g., Boardman 1986; Castillo et al. 1989; Pesticides Trust 1989; Ríos-González et al. 2013; Rosenthal 2004; Toleubayev et al. 2011; Van den Bosch 1980; Wargo 1998; Wesseling et al. 1997). Scholars and activists have long pointed to the weak capacity in developing countries to regulate pesticide use and trade (Hough 1998), and have called for bans on hazardous pesticides (Jansen 2008). In particular, exports of pesticides that are banned or restricted in an exporting country arouse public indignation. The "circle of poison" argument (positing that hazardous pesticides exported from the North to the South come back as residues in food exports to the North, for example, Galt 2008; Weir and Schapiro 1981) has also supported calls for stricter regulation of trade in pesticides. International action triggered by these concerns started to systematize, standardize, and distribute information about pesticides, rooted in a right-to-know principle. 
The United Nations (UN) system became a key player in organizing pesticide-related information in databases and designing models of how governments could use this information in governing the safe trade and use of pesticides. The World Health Organization (WHO), for example, developed a simple classification of hazardousness of pesticides, based on acute toxicity, which has become the worldwide standard for labeling pesticide products. The United Nations Environment Programme (UNEP) created the International Register of Potentially Toxic Chemicals in 1976 (now UNEP chemicals), which provided information on hazard assessments, the main uses, production and consumption of chemicals, and possible legal mechanisms and recommendations to control the risks of chemicals. Furthermore, the UNEP, the UN, and the WHO issued the United Nations Consolidated List of Products with information on regulatory actions taken by governments related to chemicals in 1983 (Winqvist 1999). In 1987, UNEP introduced the London Guidelines for the Exchange of Information on Chemicals in International Trade, which aimed at the exchange of information on economic, scientific, legal, and technical aspects of chemicals (Kummer 1999; Winqvist 1999). All these information-gathering efforts predominantly focused on what questions (for example, what are the characteristics of these chemicals? what are the risks for human health and environments?). By contrast, the UN Food and Agriculture Organization (FAO) started to collect other types of information and organized the collected information around how questions, such as, how to design best practices for handling and using pesticides? In doing so, the FAO competed with the WHO to take the lead in the pesticide issue (Hough 1998).

Although the FAO launched its first pesticide programs in the late 1950s, it took more than twenty-five years to formulate substantial guidelines on pesticide management (FAO 1990; Pesticides Trust 1989). Dinham (1991) argues that the agrochemical industry-lobbying group GIFAP (French acronym for the International Group of National Associations of Manufacturers of Agrochemical Products; now CropLife International) influenced FAO's policies for a long time as they worked together in a joint Bureau (Paarlberg 1993). This direct link was broken in 1970 under pressure from NGOs and other groups within the FAO. However, the FAO and the pesticide industry shared many of the same objectives, such as the harmonization of methods and procedures for the registration and control of pesticides. The FAO's work in the pesticide issue started to have consequences for the pesticide industry with the introduction of the Code of Conduct on the Distribution and Use of Pesticides (hereinafter "the code") in 1985. This code contains detailed guidelines on best practices regarding, among other things, the distribution of pesticides. It asks the agrochemical industry to test all products before they are exported, to submit this information to importing parties, to package and label exported products properly, and to ensure that subsidiary bodies employ the same standards as the parent company on producing and manufacturing pesticides. These FAO guidelines regarding information exchange anticipated the Rotterdam Convention and demanded that exporting countries send notifications to importing countries on the nature of the shipped pesticides and inform them about regulatory restrictions on the 
use of a pesticide in their own territory. The FAO, often in collaboration with other development agencies, worked extensively to get the code implemented in developing countries (Jansen 2003, 2008).

A controversial issue in the UNEP London Guidelines and the FAO code was the proposed inclusion therein of a PIC procedure, which would have connected trade regulation to the information provided on risks. In both cases, a provision on PIC was deleted from the draft text before final approval. PIC was included in seven of the eight drafts of the FAO code but removed at the final stage, according to Hough (1998; see also Hough 2003), a result of pressure from the agrochemical industry as well as the United States, the United Kingdom, and Germany.

The exclusion of a PIC procedure stimulated NGOs and activists, including Oxfam, Novib, and the Pesticide Action Network (PAN), to launch a concerted campaign to incorporate PIC in such codes. These groups mobilized country representatives of developing countries in the Group of 77 to push for such an inclusion. Eventually this led to UNEP pledging in 1987 to incorporate PIC in the London Guidelines in its next session in 1989. Similarly, the FAO passed a resolution to add PIC to the code at its next conference in 1989. In 1989, PIC was included in the London Guidelines and the code (FAO 1990). FAO took the lead on pesticides, and UNEP was the lead agency for other chemicals through its International Register of Potentially Toxic Chemicals (Murray 1994). The FAO-UNEP joint group of experts on PIC was established to guide and develop the process (Dinham 1993a). In 1992, a joint program on the PIC procedure was implemented (Murray and Logan 2004). The PIC procedure as designed in the FAO's code was a voluntary guideline.

The industry organization GIFAP initially opposed inclusion of PIC in the code but changed its position and accepted a voluntary PIC in the 1990s (CropLife International 2004; Hough 1998). Hough (1998, 2003) explains this change as resulting from a fear of more stringent and potentially mandatory alternatives. For example, a US bill that proposed pesticide export controls, introduced in 1991-1992, was considered a bigger threat than import controls. Initially, GIFAP argued against this bill by underlining possible contradictions with the FAO code (Hough 1998, 2003). Gradually, GIFAP came around to the view that being seen as responsible and concerned could serve the interests of their members (Dinham 1991). Another reason could be that the research-based pesticide companies dominating GIFAP wanted to fence off competition from generic pesticide producers by accepting higher levels of risk regulation and elimination of older, off-patent pesticides (Clapp 2003).

Advocacy groups such as PAN also shifted position by recognizing that they needed the support of the agrochemical industry to ensure that no chemicals were exported without importer consent (Dinham 1993b). They supported a voluntary PIC procedure as a first step, though kept pushing for a binding PIC procedure. The opening for a mandatory agreement came with the United Nations Conference on Environment and Development Earth Summit in 1992 (Hough 2000), which stated that the full participation of states in the PIC procedure 
should be ensured by 2000 (chapter 19 of Agenda 21). A UNEP-FAO Intergovernmental Negotiating Committee thus started in 1996 to draft a mandatory convention that would incorporate a PIC procedure for the pesticide trade. About one hundred governments and some NGOs participated in the negotiations.

The system of information exchange institutionalized by the Rotterdam Convention is not only based on the voluntary PIC procedure in the FAO code. A less-documented force behind the Rotterdam Convention was the work of the European Union to agree on a PIC within the community. Already in 1983, the European Parliament adopted a resolution to amend legislation on pesticides and other chemicals, making export subject to an explicit request by the importing country (Langlet 2003). Regulations adopted in 1988 and 1992 further developed the "principle of informed choice."1 Hence, when the negotiations for the international convention started, a legally binding form of export notification and PIC was already functioning within the European Union and the community had an interest in establishing a rather stringent international regime (Langlet 2003). Heyvaert (2009) discusses the multiple incentives for the European Union to shape international chemical governance according to its own systems already in place. The Rotterdam Convention resembles important elements of EU regulation, ${ }^{2}$ and although the latter is more progressive because a larger number of chemicals are subject to PIC, it also applies to nonparties, and it imposes an absolute export ban on some chemicals (Langlet 2003).

Kummer (1999) describes the major points of discussion during the negotiations of the convention. First, a US-led group succeeded in narrowing the negotiating mandate by limiting the convention solely to the PIC procedure as it was being applied voluntarily to date, against the wishes of a EU-led group that preferred to extend the convention to the management of chemicals more generally. Second, different positions emerged as to how broad the inclusion of chemicals should be: for example, whether only acutely hazardous formulations or also those with chronic effects should be included. A third contentious issue was the number of countries and regions with regulatory actions needed to trigger the process of including chemicals in the PIC procedure. Fourth, much discussion took place regarding the modalities of notification, packaging, and labeling. Fifth, the relation between the convention and other international agreements, in particular the World Trade Organization (WTO), remained contested: the US-led group stressed that priority should be given to the WTO agreements, whereas the EU-led group strongly opposed this. On this point, countries reached agreement only in the last session. Sixth, different views existed on funding developing countries to implement the convention and its corresponding financial mechanisms. Proposals reflecting the requests by developing countries for financial mechanisms were removed from the draft text. Because of the final compromises over these issues, the convention is narrower in scope than the voluntary mechanism of the FAO code. ${ }^{3}$

The convention was adopted in 1998 and entered into force in 2004 (as of April 2012, 148 parties had ratified it). It uses familiar instruments such as the conferences of parties (which decides about amendments and adding chemicals to annex III, the list of chemicals to 
which the PIC procedure applies), ${ }^{4}$ designated national authorities, and a secretariat (jointly managed by the UNEP and the FAO). A chemical-review committee consisting of government-designated experts reviews the information on specific pesticides and participates in the preparation of "decision guidance documents" and recommendations, used by the conference of parties to make decisions on the addition of chemicals to annex III and by parties to prepare import responses for the pesticides included in the PIC procedure. The convention is only binding for parties to the convention and thus has no direct impact on nonparties. ${ }^{5}$

\section{Institutionalizing Transparency}

\section{Organizing Information Disclosure}

The Rotterdam Convention organizes information exchange on chemicals and pesticides around two provisions. The first one is a PIC procedure that applies to the chemicals listed in annex III of the convention. Parties are obliged to prepare an import response for the listed chemicals (stipulating whether or not or under what conditions consent is given to import a chemical). ${ }^{6}$ Exporting parties are required to respect these decisions and not to export chemicals without consent.

The procedure to evaluate a chemical for inclusion in annex III can start only after receipt of notifications of a final (domestic) regulatory action for a particular chemical taken by parties. Two notifications from two different so-called geographically based PIC regions are required (article 5.5) to qualify a banned or severely restricted chemical for the PIC procedure. ${ }^{7}$ The seven PIC regions are Africa, Asia, Europe, Latin America and the Caribbean, Near East, North America, and South Pacific (COP 2004). Because the addition of pesticides to annex III depends on consensus in the COP, one party can block placing a pesticide on the list (McDorman 2004).

Because the convention aims to address the needs of developing countries, it has created a special, less burdensome procedure for severely hazardous pesticide formulations (SHPF) that pose high risks under the conditions of use in developing countries. This category of chemicals requires only one notification from a developing country. This trajectory institutionalizes differences between parties of the convention.

The second provision of information exchange concerns the collection and distribution of information on final regulatory actions taken by parties to ban or severely restrict chemicals as well as the proposals from developing countries on severely hazardous pesticide formulations causing problems under conditions of use. ${ }^{8}$ This provision broadens the disclosure of information on risks and regulatory actions and goes beyond the PIC procedure, limited to the chemicals listed in annex III, because it makes information available on all chemicals restricted or banned by other parties. 
The convention has created a complex system of information flows. First, the secretariat communicates each inclusion of a chemical in annex III, together with information on the pesticide (via the decision guidance documents), to all parties. Second, the secretariat communicates all import responses to all parties and makes them publicly available on their website and in circulated documents. Third, parties must inform their chemical-exporting industry about these import responses. Fourth, parties must prepare export notifications (when an industry in their country intends to export a banned or severely restricted chemical that is not listed in annex III) and the importing countries are supposed to respond with an acknowledgment. ${ }^{9}$ Fifth, article 13 outlines which information should accompany exported chemicals. $^{10}$

\section{Unresolved Implementation Issues}

Involved actors point to several challenges that the regime faces in institutionalizing governance by disclosure and improving implementation of the convention. The first concerns the slow institutionalization and implementation of PIC itself. Since the convention entered into force, only four pesticides have been listed as qualifying for the PIC procedure, one at the fourth conference of the parties to the convention in 2008 and the other three at the fifth conference of the parties to the convention in June 2011. ${ }^{11}$ Moreover, the secretariat speaks of "a lack of notifications and proposals of chemicals to be listed in annex III."12 The current rule of at least two notifications from two different regions strongly affects the working of the convention. According to a former PAN representative, ${ }^{13}$ a split of Europe into two PIC regions, using the argument of substantially different climatic conditions, would lead to the required number of notifications for many chemicals already notified by Europe. ${ }^{14}$ In this context, ratification of the convention by the United States (who signed the convention in 1998) could be another pathway to find the second notifications for these chemicals needed to include them in the PIC procedure. A related problem is that many notifications, in particular those of developing countries, lack scientific quality ${ }^{15}$ and are, therefore, dismissed by the chemical review committee. ${ }^{16}$ Furthermore, few developing countries use their right to propose chemicals for inclusion as an SHPF, even though such proposals require little data. ${ }^{17}$

The second challenge concerns parties' failure to take and transmit import responses for each chemical listed in annex III, which parties have to transmit to the secretariat. The average response rate (that is, parties who submitted one or more import responses) is 73 percent (until June 2011). Import responses are distributed unevenly among regions (Table 1) and pose a particular problem in Africa (e.g., Daudu 2008). ${ }^{18}$ Hence, although convention principles have become an intrinsic part of decision-making routines in, for example, the European Union, this is less the case in many developing countries. 
Table 1 Import Responses by Parties

\begin{tabular}{lccc}
\hline PIC Region & $\begin{array}{l}\text { Parties That Have } \\
\text { Submitted One or More } \\
\text { Import Response }\end{array}$ & $\begin{array}{l}\text { Parties That Have } \\
\text { Submitted No Import } \\
\text { Responses }\end{array}$ & $\begin{array}{c}\text { Average Import Response } \\
\text { Rate per Region (percent) }\end{array}$ \\
\hline Africa & 34 & 6 & 56 \\
Asia & 16 & 1 & 73 \\
Europe & 34 & 3 & 86 \\
Latin America and & 24 & 0 & 80 \\
the Caribbean & 10 & 0 & 75 \\
Near East & 1 & 0 & 100 \\
North America & 4 & 2 & 55 \\
Southwest Pacific & & 0 & $2011)$ \\
\hline
\end{tabular}

Source: Authors' communication with the Secretariat of the convention (May 2011)

Though the convention is supposed to ease decision making relating to hazardous chemicals for countries with little regulatory capacity, the implementation of the convention already requires certain regulatory knowledge and capacity, which is not always present. The convention requires the amendment or adoption of national legislative or administrative measures; establishing national databases and registers that include safety information for chemicals; providing the public with sufficient information on chemical handling, accident management and safer alternatives for the pesticides listed in annex III; and cooperation at a global, regional, and subregional levels directly or through competent international organizations. Importing parties also have to implement measures to make timely import decisions, make domestic production and import from nonparties subject to the same conditions as set out in the import decision, propose SHPFs for listing, develop notifications, and acknowledge export notifications.

Poorer developing countries cannot fulfill all these governance-by-disclosure requirements. The logical outcome is a general call for more capacity building. Within the structure of the convention, training is given and e-learning tools have been prepared in order to increase capacity in this area. The key bottleneck, however, is the lack of resources to implement a comprehensive capacity-building program. At the various conferences of parties, groups of developing countries use every opportunity to press for funding for training programs (e.g., ENB 2011), but to date developed countries have accepted only a voluntary special trust fund to strengthen national capabilities and have resisted other forms of funding, partly because of fear of setting a precedent for other treaties (Selin 2010).

The final challenge is how to address noncompliance, which goes largely unreported, and it is unclear how regularly it occurs. The conference of parties has been working on this issue ever since its first meeting, without reaching any agreement. For example, the fourth conference discussed whether the mechanism should take a facilitative and supportive 
approach or a punitive one, whereby the former would include financial and technical assistance to parties to motivate them to comply with the convention (COP 2008). Similar to other issues, the negotiations in the Rotterdam Convention are influenced by how the discussion about compliance in the Basel Convention (transboundary movement of hazardous waste) and Stockholm Convention (persistent organic pollutants) evolves (Kohler 2006; Selin 2010). In the so-called synergies process, the three conventions collaborate to strengthen their implementation.

\section{The Marketization of Disclosure}

How much is the emergence and institutionalization of the convention driven by a technostatist approach and how much by a neoliberal approach? We consider this here by assessing the extent to which the convention is market following rather than market transforming (see Gupta and Mason, this book, chapter 1). How does the convention relate to the market and does it facilitate or restrict trade? Unlike some other transparency initiatives discussed in this book, the convention itself does not depend on market mechanisms for its implementation. However, its goal is regulating trade, whereby the convention recognizes that trade and environmental policies should be mutually supportive. ${ }^{19}$ There is no explicit intention to restrict trade.

The Rotterdam Convention requires implementation via national laws that are legally binding for industry. The convention will probably affect trade of the chemicals listed in annex III; currently a large number of "no-consent" import notifications restrict imports. Hence, the PIC procedure does not simply follow market developments but instead shapes them. Of course, this applies only to specific chemicals. The convention does not restructure the market writ large nor adjusts trade obligations more generally. This may partly explain why, after their initial opposition, large pesticide corporations supported PIC. Although this governance-by-disclosure initiative is congruent with and sometimes uses neoliberal discourses, it also creates a continuous friction with the idea of market-driven decision making because of the underlying techno-statist approach that poses limits to market transactions.

\section{Effects of Transparency}

What follows is a discussion of the same typology of effects-normative (informing), procedural (empowering), and substantive (improving) - that is examined by other contributors to this book. The convention text does not limit itself to any one of these three desired effects and is, in fact, an effort to connect them. Hence, in the world of this convention, the analytical distinction among informing, empowering, and improving is not clear-cut. 


\section{Normative Effects: Transparency as Right to Know}

About the question, whether this governance-by-disclosure initiative furthers a right to know and hence informs, we can be short. Yes, it does, insofar as it organizes information exchange between governments. The importance of having access to regulatory actions of other countries is not to be underestimated. In previous research on pesticide regulation in Central America (Jansen 2003, 2008) government officials regularly asked about bans of pesticides in exporting countries of which they only had heard rumors. Nowadays, they have easy access to this information through the convention.

\section{Procedural Effects: Empowerment and Sovereignty}

\section{Transparency and empowerment}

An assessment of whether the convention leads to empowerment of information recipients (in this case, developing countries) depends on how we understand the concept of empowerment. Here, we make an analytical distinction among four modes of thinking about power, as summarized by Wolf (1999). ${ }^{20}$ In the first mode, empowerment is equated with capacity building, which means that power is conceptualized as an attribute of a person, or in this case, government, that is, as a potency or capability. As we have seen, the capacity to make informed decisions through the convention is still weak in developing countries, but one could argue that empowerment according to this mode is taking place and likely to increase. As a second form of empowerment, the increased ability of ego to impose its will on an alter ego, the effects of the convention could be considered as empowering, because developing countries will be better able-pushed by the convention-to make exporting countries comply with their import decisions and preferences. A third (stronger) meaning of empowerment, that is, increased control of a setting, can hardly be considered an outcome of the convention: developing countries are not redefining trade and trade rules in chemicals, and there is no reason to think that developing countries have become more powerful vis-àvis others in decision-making processes within convention structures. A fourth form of empowerment refers to the power to organize and operate the governance settings oneself. Historical accounts of the convention (e.g., Langlet 2009) show that developing countries have not been the driving forces behind the convention's design or operationalization. Interviewees even point out that some developing countries were not in favor of the convention initially. Accepting the successive announcements of increasing participation of developing countries on the convention website as increasing commitment, we can conclude that commitment to the convention follows the implementation process, rather than orchestrates it.

In short, only by using a narrow interpretation of empowerment (the first mode as increased capacity), rooted in a nonrelational concept of power, can one conclude that the 
Rotterdam Convention leads to the empowerment of information recipients. If a more comprehensive definition of empowerment is used, which includes the relations between developed and developing countries and the power to structure the field of action of others, we can conclude that there has been very little empowerment through transparency and disclosure in this case.

\section{Transparency and sovereignty}

Let us now address how the convention relates to democratization (or the rights-based democratic push for individual liberty, choice, and participation, particularly vis-à-vis citizens or civil society) and state sovereignty. The Rotterdam Convention is a case in which governance by disclosure strengthens rather than weakens sovereignty. The aim of the convention is to help states decide about and control imports of risky substances into their jurisdiction. The critical importance of risk mitigation and reduced environmental harm, and the state-to-state character of information flows, implies that issues of accountability, legitimation, and democracy (particularly vis-à-vis citizens or civil society) are relatively less central here compared to some other transparency initiatives (Biermann and Gupta 2011; Mitchell 2011). Instead, the right to know of governments, democratic or not, is the central issue. This transparency initiative thus has stronger roots in a techno-statist Keynesian governance approach to regulating technology risks rather than in a deliberative democracy approach to risk governance. Based on this case study, we reject, therefore, the hypothesis posted in chapter 1 (Gupta and Mason) of this book that transparency decenters state-led regulation. In the form of governance by disclosure between states, transparency may strengthen state-led regulation.

This does not mean that civil society advocacy has been unimportant in the shaping of this case of governance by disclosure. International activism on pesticides focused much of their work on getting the PIC procedure in place. The interviewed NGO representative stated that getting the PIC procedure functioning was their priority, ${ }^{21}$ being in fact the raison d'être of the Pesticide Action Network. The pesticide activists were willing and able to adopt a long-term strategy toward procedural change (Pesticides Trust 1989; see also Dinham 1991, 1993a, 1993b, 1996, 2004). The transparency literature (e.g., Gupta 2008) sometimes argues that successful governance by transparency requires intermediary groups. However, for the Rotterdam Convention to function in the future, that seems to be less the case. The possibility of shaming by intermediates or environmentalist groups hardly plays a role in the PIC mechanism. This does not mean that NGOs cannot contribute; they are observers at meetings just like the industry, and they sometimes provide inputs into the discussions. However, this form of governance by disclosure, once in place, no longer depends on them. 


\section{Substantive Effects: Disclosure-Based Governance and Bans}

A crucial issue in the transparency debate is the possible trade-offs between procedural and substantive improvements, and whether the procedural turn or "getting the process" right is not more than a distraction, diverting time and resources from substantive outcomes (Gupta 2008). Improvement has a double meaning in Rotterdam Convention: to improve the regulatory capacity of developing countries and countries in economic transition and to improve environmental and human health. Interviewees tended to be concerned about both types of improvements. We argue that despite its modest impact to date and the limitedness of its scope, the procedural turn induced by the convention strengthens the capacity of states to manage risks in the long term. The convention is making small contributions to improving the risk infrastructure of developing countries and has improved access to information about regulatory decisions and supporting scientific evidence. The implementation challenges previously discussed can be addressed within the framework of the convention. Why nonetheless is the impact limited? We discuss two reasons: first, the number and nature of chemicals listed in annex III, and second, the extent to which a PIC procedure can cover the spectrum of governance challenges posed by pesticide use. We conclude with assessing the link between PIC and a trade ban.

\section{Pesticides subject to PIC}

Many of the listed chemicals in annex III are outdated pesticides that are not widely used or traded. There are thus few objections to their inclusion (Langlet 2009). Of the forty chemicals listed in annex III, the European Union exported only eight (including chemicals that received more than five export notifications in the European Union in the period 2003-2011; EDEXIM 2011b). When notifications concern chemicals still widely used and thus with larger trade interests, exporting countries object more strongly to their inclusion. The two major, almost iconic, examples to date are chrysotile asbestos and endosulfan, for which the Rotterdam Convention chemical review committee has drafted a decision guidance document. Because decisions of the conference of parties require consensus, countries with export interests can block listing of such important chemicals relatively easily. A group led by India, for example, has opposed the listing of endosulfan in the convention, and a group led by Canada, the largest producer, has opposed the listing of chrysotile asbestos (Bitonti 2009) and has played a leading role in keeping this chemical out of annex III of the convention. ${ }^{22}$ Endosulfan was finally approved for inclusion in annex III by the conference of parties to the convention in 2011. The opposition may have been dropped because the Stockholm Convention on Persistent Organic Pollutants included endosulfan in the list of chemicals that have to be eliminated in May 2011. The Stockholm Convention is more farreaching in its immediate effects on trade than is the Rotterdam Convention, given that the 
latter's focus is on informing about, rather than banning, a substance (but see the following for a more detailed discussion of this).

One key test for the Rotterdam Convention's substantive impact in the long term is thus whether the list with chemicals subject to the PIC procedure will grow over time. It is too early to conclude that the recent inclusion (2011) of endosulfan is a turning point, but it may signal future inclusion of more widely used chemicals with a high economic value. This recent inclusion shows that chemicals that are part of the current package of popular pesticides in developing countries can also become subject to stricter regulatory control. The next litmus test is the discussion about the widely used herbicide paraquat at the sixth conference of the parties to the convention.

\section{PIC and the spectrum of governance challenges}

In addition to the limited number of pesticides currently listed in annex III, another hurdle to substantive impacts is that the convention addresses only a small component of the whole pesticide chain of production, trade, and use, namely, the moment of export and import. It does not tackle problems related to, for example, pesticide handling during use. In general, developing country governments do not adequately address the unsafe use of pesticides in developing country conditions (Jansen 2008; Karlsson 2007). The sound science and best practice principles that underlie global governance treaties such as the Rotterdam Convention are often at odds with the conditions that lead to unsound practices in farmers' fields.

\section{The ban as regulatory instrument}

The observation that poor farmers in developing countries are unable to use hazardous pesticides safely (due to, among others, illiteracy, lack of resources to buy personal protection equipment, and tropical circumstances that make it very difficult to use such equipment) has long motivated many activists to call for bans and other forms of restrictive regulation. Governance by disclosure and PIC are often seen as an alternative to the ban. Gupta, for example, considers PIC as a compromise between two alternative policy options, meaning "an outright ban on trade as a way to avoid harm, versus a caveat emptor or 'let the buyer beware' approach where the onus to know about and avoid harm rests solely with a buyer" (Gupta 2010a, 33). A nonbanning narrative certainly underpins the Rotterdam Convention. It is often remarked that the convention is not designed to ban chemicals or pesticides but to provide information on the risks of chemicals so that countries can make informed decisions on their import (Murray and Logan 2004). For example, the two first speakers at the fourth conference of parties to the convention in 2008 opened with statements that the convention is not about banning chemicals (ENB 2008). Persons involved in the convention do not hesitate to stress that "it has to be kept in mind that listing a chemical in annex III does not mean that the chemical is banned, but requires parties to exchange all necessary information on this chemical in order to make informed decisions related to its import.”23 
It is in this context that the shift by advocacy groups from their initial activist position to prohibit exports of banned pesticides to an embrace of PIC has been important. From the perspective of the Pesticide Action Network, the choice was either to ban the export of hazardous pesticides or to let importing countries decide whether they wanted to import them or not. ${ }^{24}$ PAN was concerned that the first option could result in a shift of the production of these pesticides to countries with less strict export regulations. Furthermore, the second option was more consistent with the principle that developing countries should have the right to decide what to import rather than have the North decide what to export.

The relevant question now is whether the idea of PIC as an alternative to the ban, confidently expressed in nonbanning narratives, really means that the ban as regulatory instrument has disappeared from global pesticide regulation. We do not think so; there are several reasons why the ban can be considered a fundamental part of contemporary pesticide governance, probably more than ever, even though PIC is generally seen as an alternative to an outright ban. A pesticide qualifies for inclusion in the PIC list (annex III) when at least two countries from two different PIC regions have banned a pesticide or severely restricted its use as a final regulatory action. In fact, the convention provides for the first time a globally recognized definition of a ban. ${ }^{25}$ According to a former PAN representative, ${ }^{26}$ the convention's definition of "banned chemical” dispelled confusion resulting from different interpretations by NGOs and industry of previous listings of chemicals as banned by UNEP. A remarkable, though yet little discussed, implication of the convention's definition is that withdrawal of a chemical from the regulatory process by industry may (under certain conditions) be seen as a ban of a chemical. This is quite a novel interpretation.

In practice, some developing countries seem to take the listing of a chemical in annex III itself as an indication of a ban (which is logical, because most of the listed chemicals have been banned in at least some countries). The industry contests this type of decision making: "Unfortunately some parties use the Annex of the Rotterdam Convention as a black list and wrote legislation to ban all listed chemicals without making independent decisions as sovereign states based on the provided information. ${ }^{27}$ The interviewed designated national authority confirmed this practice and similar to the industry representative denounced it, though for a different reason: he was afraid that some governments might block the listing of a particular chemical precisely because they perceive the listing as a ban rather than just a step toward better information exchange.

Although the specter of a ban may have pushed actors to seek compromise around PIC, this does not mean that it is an alternative to the ban. Despite the dominance of a nonbanning discourse, the ban has become a core practice of and a central condition for risk governance and regulatory practice. The ban as regulatory action is a substantial element of decision making as per the PIC mechanism. Therefore, the notion of a ban relates in complex ways to PIC, rather than being in opposition to it. 


\section{Conclusion}

The Rotterdam Convention does not seem to be one of those transparency systems that are "tacked together in times of crisis" (Fung et al. 2007, 106). Instead, it has taken several decades to arrive at a more-or-less functioning, though modest, governance-by-disclosure regime in this case. The PIC system seems to deliver the public benefits that policy makers aimed for. We conclude that more information regarding regulatory decisions on banning and restricting the use of pesticides, together with scientific evidence of harm, has become available. The convention combines procedural and substantive elements because it fosters informing and improving capacity and environmental conditions. We have also argued that, in a limited form, the convention shapes trade rather than being trade or market following, though it has to accept that trade interests lobby at the level of individual countries. In terms of empowerment, the results are more ambiguous. If one views empowerment as bringing about shifts in unequal power relations, little has been achieved in this transformative sense. If one views empowerment as capacity building or the improved ability to take informed decisions, then some advances can be reported.

Rather than an exercise in deliberative democracy, the convention is being driven by a techno-statist approach. The case also illustrates that not all transparency initiatives can be explained by reference to the marketization driver. The history of the negotiations and institutionalization of the convention shows that it is based on, and results in, the strengthening of sovereignty instead of a decentering of state-led regulations. It increases the legitimacy and the capacity of state regulators in developing countries to control trade and use of hazardous chemicals and manage risks. Science, in the form of government appointed experts, is seen as independent from market actors and the key source of authority to interpret risk information. Concerned persons from advocacy groups, the scientific community, and government officials consider techno-statist risk regulation, based on improved access to information, as the most appropriate way to reduce pesticide risks.

What is remarkable in this case is the long trajectory needed to shape a PIC mechanism. As the regime evolves, it remains to be seen whether all parties will be willing to accept potentially more onerous disclosure "costs" in the future. For now, many countries are not even able to make the obligatory import decisions about the PIC-listed chemicals. Furthermore, to date, only a small group of chemicals is included within the purview of the convention, but now that the PIC mechanism is in place, more may well be added. This next step will take time. The convention's history shows that the key issue for reflexive transparency is not so much a "loss of innocence" but rather letting go of a naive belief that these multilateral and complex processes will yield revolutionary changes in the short term. 


\section{Notes}

1. Regulation (EEC) No. 1734/88 and No. 2455/92. The strongest opponents were the United Kingdom, Germany, and France, who preferred voluntary arrangements with the industry.

2. In turn, after the adoption of the convention, the EC developed new regulation to bring it fully in line with the convention (see for more details Langlet 2003, 2009).

3. After the adoption of the binding convention, the FAO removed PIC from its voluntary code (FAO 2003).

4. The conferences of parties are open to other parties (article 18.7). The UN, its specialized agencies, and the International Atomic Energy Agency, as well as states that are not party, industry representatives, and NGOs, may attend the meetings as observers.

5. However, when the importing party decides not to consent to the import of a chemical, it has to prohibit the import from any other source, including nonparties.

6. When a party decides not to consent to import, this should apply to imports from nonparties as well, and if the substance is domestically produced, such production should also stop.

7. A severely restricted chemical is a chemical for which a "final regulatory action" in a member country prohibits almost all uses in one or more categories. A banned chemical is a chemical for which a final regulatory action prohibits all uses in one or more categories.

8. Article 14 of the convention sets out the information to be shared between the parties, regardless if the chemical is exported or not. This includes technical, scientific, economic, and legal information on SHPFs, banned and severely restricted chemicals, as well as information on regulatory actions taken domestically. Confidential information can be protected but information requirements of the convention cannot be confidential.

9. The mechanism of export notifications does not apply to chemicals listed in annex III (to which the PIC procedure applies). In contrast to the PIC procedure, the export notification procedure does not require consent of the importing party before export; here the responsibility for taking measures lies with the importing party.

10. For example, for chemicals listed in annex III and banned or severely restricted chemicals in the party's own territory, information on risks and hazards for the environment and human health should be indicated on a safety data sheet in an internationally recognized format.

11. At the time of writing, the agenda for the sixth conference of the parties to the convention added another six chemicals for evaluation, including the controversial chemical paraquat.

12. Author e-mail communication with the convention secretariat, Geneva, June 2011.

13. Author interview with a former Pesticide Action Network representative, London, June 2011.

14. The European Community has listed (as of September 5, 2011) sixty-two chemicals qualifying for PIC notification, including pesticides that inflict many casualties in developing countries, such as carbofuran, methamidophos, methyl-parathion, and paraquat (EDEXIM 2011a). Inclusion of any of these sixty-two pesticides in the convention's assessment process depends on a notification from at least one other region.

15. Author interview with a chemical review committee expert, May 2011.

16. For example, notifications from Malawi, Iran, Malaysia, Sweden (CRC 2010), Syrian Arabic Republic, and Japan (CRC 2011) were declined.

17. The secretariat remarks that a proposal still requires field monitoring, data collection, and validation.

18. As of April 30, 2012, thirteen parties have failed to provide any import responses: Botswana, Djibouti, Equatorial Guinea, Lesotho, Maldives, Marshall Islands, Montenegro, Namibia, Russian Federation, Saint Vincent and the Grenadines, Somalia, Tonga, and Ukraine.

19. During the negotiations in the mid-1990s, the United States argued that the convention should not affect rights and obligations flowing from WTO agreements, whereas the European Union opposed this view (Kummer 1999). A sufficiently vague formulation in the preamble was agreed on to create consensus, stating that "nothing in this convention shall be interpreted as implying in any way a change in the rights and obligations of a Party under any existing international agreement." 
20. For an interesting discussion of power that covers the same elements as Wolf, but makes a slightly different distinction, see Fuchs (2005).

21. Author interview with a former representative of the Pesticide Action Network, London, June 2011.

22. As of April 2013, asbestos has appeared again on the agenda of the convention (at the sixth conference of the parties to the convention). The Canadian government has declared that it will no longer oppose the inclusion of asbestos in annex III. This is a result of a shift in the Quebec government in 2012, with the newly elected Parti Québécois ending government support for the Quebec asbestos industry (Ruff 2012).

23. Author e-mail communication with secretariat of the convention, Geneva, June 2011.

24. Author interview with a former representative of Pesticide Action Network, London, June 2011.

25. "'Banned chemical' means a chemical all uses of which within one or more categories have been prohibited by final regulatory action, in order to protect human health or the environment. It includes a chemical that has been refused approval for first-time use or has been withdrawn by industry either from the domestic market or from further consideration in the domestic approval process and where there is clear evidence that such action has been taken in order to protect human health or the environment" (Article 2.b; italics added). This overlaps is almost the same the definition as in Regulation (EC) No 304/2003; the only difference is the extra word clear. The convention does not explain what clear means.

26. Author interview with a former Pesticide Action Network representative, London, June 2011.

27. Author e-mail communication with a large pesticide corporation representative, July 2011.

\section{References}

Biermann, Frank, and Aarti Gupta. 2011. Accountability and Legitimacy in Earth System Governance: A Research Framework. Ecological Economics 70 (11):1856-1864.

Bitonti, Christopher P.H. 2009. Exporting Ignorance: Canada's Opposition to the Regulation of the International Chrysotile Asbestos Trade Under the Rotterdam Convention. Asper Review of International Business and Trade Law 9:171-199.

Boardman, Robert. 1986. Pesticides in World Agriculture: the Politics of International Regulation. Basingstoke: Macmillan.

Castillo, L., C. Wesseling, H. Aguilar, C. Castillo, and P. de Vos. 1989. Uso e impacto de los plaguicidas en tres países centroamericanos. Estudios Sociales Centroamericanos 49:119-139.

Clapp, Jennifer. 2003. Transnational Corporate Interests and Global Environmental Governance: Negotiating Rules for Agricultural Biotechnology and Chemicals. Environmental Politics 12 (4):1-23.

COP. 2004. Report of the Conference of the Parties to the Rotterdam Convention on the Prior Informed Consent Procedure for Certain Hazardous Chemicals and Pesticides in International Trade on the Work of its First Meeting. Geneva: Rotterdam Convention.

2008. Report of the Conference of the Parties to the Rotterdam Convention on the Prior Informed Consent Procedure for Certain Hazardous Chemicals and Pesticides in International Trade on the Work of its Fourth Meeting. Rome: Rotterdam Convention.

CRC. 2010. Report of the Chemical Review Committee on the Work of its Sixth Meeting. Geneva: Rotterdam Convention. 
2011. Report of the Chemical Review Committee on the Work of its Seventh Meeting. Geneva:

Rotterdam Convention.

CropLife International. 2004. Prior Informed Consent (PIC). Position paper CropLife.

Daudu, Olurotimi Williams. 2008. National Implementation of and Compliance with the Rotterdam Convention:

A Perspective from African Countries. PhD Dissertation, University of Calgary.

Dinham, Barbara. 1991. FAO and Pesticides: Promotion or Proscription? The Ecologists 21 (2):61-65.

1993a. Controlling Hazardous Trade: the Potential of Prior Informed Consent. The Pesticide News (21):10-11.

. 1993b. The Pesticide Hazard: A Global Health and Environmental Audit. London: Zed.

1996. The Success of a Voluntary Code in Reducing Pesticide Hazards in Developing Countries. In Green Globe Yearbook of International Co-operation on Environment and Development 1996, edited by

H. O. Bergesen, G. Georg Parmann and Ø. B. Thommessen. Oxford: Fridtjof Nansen Institute and Oxford University Press.

. 2004. Can New Global Initiatives Reduce Pesticide Hazards? Pesticides News 65:6-8.

EDEXIM. 2011a. Number of Yearly Export Notifications per Chemical. www.edexim.jrc.it (accesss date: 5 September 2011).

2011b. List of Chemicals Subject to Export Notification Procedure. www.edexim.jrc.it (accesss date: 5 September 2011).

ENB. 2008. Summary of the Fourth Meeting of the Conference of the Parties to the Rotterdam Convention: 2731 October 2008. Earth Negotiations Bulletin 15 (168).

ENB. 2011. Summary of the Fifth Meeting of the Rotterdam Convention on Prior Informed Consent: 20-24 June 2011. Earth Negotiations Bulletin 15 (188).

Etzioni, Amitai. 2010. Is Transparency the Best Disinfectant? The Journal of Political Philosophy 18 (4):389404.

FAO (Food and Agriculture Organization of the United Nations). 1990. International Code of Conduct on the Distribution and Use of Pesticides. (Amended to include Prior Informed Consent in Article 9 as adopted by the 25th Session of the FAO Conference in November 1989). Rome: FAO.

—. 2003. International Code of Conduct on the Distribution and Use of Pesticides. (Revised Version, adopted by the 123rd Session of the FAO Council in November 2002). Rome: FAO.

Florini, Ann. 1998. The End of Secrecy. Foreign Policy 111:50-63.

Fox, Jonathan. 2007. The Uncertain Relationship between Transparency and Accountability. Development in Practice 17 (4-5):663-671.

Fuchs, Doris. 2005. Commanding Heights? The Strength and Fragility of Business Power in Global Politics. Millennium - Journal of International Studies 33 (3):771-801.

Fung, Archon. 2013. Infotopia: Unleashing the Democratic Power of Transparency. Politics and Society 41 (2):183-212.

Fung, Archon, Mary Graham, and David Weil. 2007. Full Disclosure: The Perils and Promise of Transparency. Cambridge: Cambridge U.P.

Galt, Ryan. 2008. Beyond the Circle of Poison: Significant Shifts in the Global Pesticide Complex, 1976-2008. Global Environmental Change 18 (4):786-799. 
Gupta, Aarti. 2008. Transparency under Scrutiny: Information Disclosure in Global Environmental Governance. Global Environmental Politics 8 (2):1-7.

_. 2010a. Transparency in Global Environmental Governance: A Coming of Age? Global Environmental Politics 10 (3):1-9.

— 2010b. Transparency as Contested Political Terrain: Who Knows What about the Global GMO Trade and Why does it Matter? Global Environmental Politics 10 (3):32-52.

Heyvaert, Veerle. 2009. Globalizing Regulation: Reaching Beyond the Border of Chemical Safety. Journal of Law and Society 36 (1):110-128.

Hough, Peter. 1998. The Global Politics of Pesticides: Forging Consensus from Conflicting Interests. London: Earthscan.

_ 2000. Institutions for Controlling the Global Trade in Hazardous Chemicals: The 1998 Rotterdam Convention. Global Environmental Change 10 (2):161-164.

- 2003. Poisons in the System: The Global Regulation of Hazardous Pesticides. Global Environmental Politics 3 (2):11-24.

INC. 1998. Report of the Intergovernmental Negotiating Committee for and International Legally Binding Instrument for the Application of the Prior Informed Consent Procedure for Certain Hazardous Chemicals and Pesticides in International Trade on the Work of its Fifth Session. Brussel: Rotterdam Convention.

Jansen, Kees. 2003. Crisis Discourses and Technology Regulation in a Weak State: Responses to a Pesticide Disaster in Honduras. Development and Change 34 (1): 45-66.

Jansen, Kees. 2008. The Unspeakable Ban: The Translation of Global Pesticide Governance into Honduran National Regulation. World Development 36 (4):575-589.

Karlsson, Sylvia I. 2007. Strategies for Reducing Risks with Agricultural Pesticides in Developing Countries. International Journal of Social Economics 34 (1/2): 103-126.

Kohler, Pia M. 2006. Science, PIC and POPs: Negotiating the Membership of Chemical Review Committees under the Stockholm and Rotterdam Conventions. RECIEL Review of European Community and International Environmental Law 15 (3):293-303.

Kummer, Katharina. 1999. Prior Informed Consent for Chemicals in International Trade: The 1998 Rotterdam Convention. RECIEL Review of European Community and International Environmental Law 8 (3):323330.

Langlet, David. 2003. Prior Informed Consent for Hazardous Chemicals Trade-Implementation in EC Law. European Environmental Law Review 12 (11):292-308.

2009. Prior Informed Consent for Hazardous Trade: Regulating Trade in Hazardous Goods at the Intersection of Sovereignty, Free Trade and Environmental Protection. Alphen aan de Rijn: WoltersKluwer.

McDorman, Ted L. 2004. The Rotterdam Convention on the Prior Informed Consent Procedure for Certain Hazardous Chemicals and Pesticides in International Trade: Some Legal Notes. RECIEL Review of European Community and International Environmental Law 13 (2):187-200.

Mitchell, Ronald B. 2011. Transparency for Governance: The Mechanisms and Effectiveness of Disclosurebased and Education-based Transparency Policies. Ecological Economics 70 (11):1882-1890. 
Mol, Arthur P.J. 2010. The Future of Transparency: Power, Pitfalls and Promises. Global Environmental Politics 10 (3):132-143.

Murray, William, and Sheila. Logan. 2004. The Rotterdam Convention: Why Is It Here and What Is It Trying to Achieve? UNEP Industry and Environment 27 (2-3):9-11.

Murray, William J. 1994. Organization and targets of the prior informed consent notification scheme. Part I.

Development and implementation. Annali dell'Istituto Superiore di Sanita 30 (4):383-386.

Paarlberg, Robert L. 1993. Managing Pesticide Use in Developing Countries. In Institutions of the Earth: Sources of Effective International Environmental Protection, edited by P.M. Haas, R.O. Keohane and M.A. Levy. Cambridge: MIT Press.

Pesticides Trust. 1989. The FAO Code: Missing Ingredients. Prior Informed Consent in the International Code of Conduct on the Distribution and Use of Pesticides. London: The Pesticides Trust.

Ríos-González, Adriana, Kees Jansen, and Héctor Javier Sánchez-Pérez. 2013. Pesticide Risk Perceptions and the Differences between Farmers and Extensionists: Towards a Knowledge-in-Context Model. Environmental Research http://dx.doi.org/10.1016/j.envres.2013.03.006.

Rosenthal, Erika. 2004. The DBCP Pesticide Cases: Seeking Access to Justice to Make Agribusiness Accountable in the Global Economy. In Agribusiness and Society: Corporate Responses to Environmentalism, Market Opportunities and Public Regulation, edited by K. Jansen and S. Vellema. London: Zed.

Rotterdam Convention. 2008. Rotterdam Convention on the Prior Informed Constent Procedure for Certain Hazardous Chemicals and Pesticides in International Trade (revised in 2008).

Ruff, Kathleen. 2012. Quebec and Canadian Governments End Their Historic Support of the Asbestos Industry. International Journal of Occupational and Environmental Health 18 (4):263-267.

Selin, Henrik. 2010. Global Governance of Hazardous Chemicals: Challenges of Multilevel Management. Cambridge: MIT Press.

Toleubayev, Kazbek, Kees Jansen, and Arnold Van Huis. 2011. From Integrated Pest Management to Indiscriminate Pesticide Use in Kazakhstan. Journal of Sustainable Agriculture 35 (4):350-375.

Tyfield, David. 2012. A Cultural Political Economy of Research and Innovation in an Age of Crisis. Minerva 50 (2):149-167.

Van den Bosch, Robert. 1980. The Pesticide Conspiracy. Dorchester: Prism Press.

Wargo, John. 1998. Our Children's Toxic Legacy: How Science and Law Fail to Protect Us from Pesticides. New Haven: Yale UP.

Weir, David, and Mark Schapiro. 1981. Circle of Poison: Pesticides and People in a Hungry World. San Francisco: Food First Books.

Wesseling, Catharina, Rob McConnell, Timo Partanen, and Christer Hogstedt. 1997. Agricultural Pesticide Use in Developing Countries: Health Effects and Research Needs. International Journal of Health Services 27 (2):273-308.

Winqvist, Tina. 1999. Trade in Domestically Prohibited Goods. Winnipeg: International Institute for Sustainable Development.

Wolf, Eric R. 1999. Envisioning Power: Ideologies of Dominance and Crisis. Berkeley: University of California Press. 